\title{
Effects of Phellinus linteus Administration on Serotonin Synthesis in the Brain and Expression of Monocarboxylate Transporters in the Muscle during Exhaustive Exercise in Rats
}

\author{
Jin-Hee SEO ${ }^{1}$, Yun-Hee Sung ${ }^{1}$, Ki-Jeong KIM ${ }^{1}$, Mal-Soon SHIN ${ }^{1}$, \\ Eun-Kyu LEE ${ }^{1,2}$ and Chang-Ju KIM ${ }^{1, *}$ \\ ${ }^{1}$ Department of Physiology, College of Medicine, Kyung Hee University, \#1 Hoigi-dong, \\ Dongdaemoon-gu, Seoul 130-701, Republic of Korea \\ ${ }^{2}$ Department of Internal Medicine, Andong Medical Group, \#574-2 Susang-dong, Andong, \\ Kyungbuk 760-410, Republic of Korea
}

(Received November 16, 2010)

\begin{abstract}
Summary This study was conducted to determine the effects of Phellinus linteus (PL) on serotonin synthesis in the brain and on the expression of monocarboxylate transporters (MCTs) in muscles during exhaustive exercise in rats. In this study, 60 male Sprague-Dawley rats were divided into the following 6 groups: control; exercise; exercise and $50 \mathrm{mg} / \mathrm{kg}$ of PL treatment; exercise and 100 of $\mathrm{mg} / \mathrm{kg}$ PL treatment; exercise and $200 \mathrm{mg} / \mathrm{kg}$ of PL treatment; and exercise and $100 \mathrm{mg} / \mathrm{kg}$ of caffeine treatment. Treatment with $200 \mathrm{mg} / \mathrm{kg}$ of PL led to a significant increase in the time to exhaustion in response to running on a treadmill and a significant decrease in 5-hydroxytryptamine synthesis and tryptophan hydroxylase expression in the dorsal raphe of rats. MCT1 and MCT4 expression of the gastrocnemius muscles was also increased in response to treatment with $200 \mathrm{mg} / \mathrm{kg}$ of PL. The results of the present study demonstrated that the administration of PL increased endurance exercise performance through inhibition of serotonin production in the brain and increased the expression of MCT1 and MCT4 in muscles. These results suggest that PL exerts an ergogenic effect.
\end{abstract}

Key Words Phellinus linteus, exhaustive performance, 5-hydroxytryptamine, tryptophan hydroxylase, monocarboxylate transporters

The neurotransmitter serotonin (5-hydroxytryptamine [5-HT]) has a variety of effects on respiratory neuronal activity $(1,2)$. For example, 5-HT is causally involved in multiple central nervous facets of mood control, as well as the regulation of sleep, anxiety, alcohol intake, drug abuse, food intake, and sexual behavior (3). The variability in the effects of exogenous and endogenous 5-HT may be due to the subtypes of 5-HT receptors that are preferentially expressed (1). In the first step in the biosynthesis of serotonin, tryptophan hydroxylase (TPH) catalyzes the formation of 5-hydroxytryptophan (4). TPH is also the rate-limiting enzyme in serotonin production, and its expression has been used as an indicator of serotonin synthesis (5).

Prolonged exhausting exercise inevitably leads to fatigue, which is a complex multifactorial phenomenon that involves peripheral and central components. The induction of fatigue in response to an increase in the serotonin concentration in the brain has been described in experimental animals (6-8). Additionally, an increase in serotonin levels has been found to inhibit descending motorneurons in animals (9). Fatigue caused by an increase in the concentration of brain

*To whom correspondence should be addressed.

E-mail: changju@khu.ac.kr serotonin has been referred to as central fatigue (10). This type of fatigue is known to limit endurance exercise performance via deterioration in brain function $(11,12)$.

The monocarboxylate transporters (MCTs) are a family of proteins that are expressed in tissue-specific patterns in human and animal muscles (13), and MCT isoforms (MCT1-14) have been identified (14). It has been suggested that MCT1 and MCT4 are the key transporters involved in the regulation of the lactate flux across the plasma membrane (15). In human and rat skeletal muscles, MCT1 expression is highly correlated with indices of oxidative capacities of muscles $(16,17)$. Additionally, MCT1 plays a major role in the influx of lactic acid for oxidation $(13,18,19)$. MCT4 is primarily expressed in fast-twitch fibers, and its expression is associated with indices of glycolytic capacity (20). It has also been suggested that MCT4 plays a primary role in the efflux of lactate from muscle fibers, especially in white muscle fibers, during intense exercise $(18,21)$. MCT4 protein expression is less easily perturbed by muscle activity, apparently requiring more intense exercise to be up-regulated $(17,20,22)$. MCT1 and MCT4 are co-expressed in muscles; however, MCT1 is more prevalent in type I fibers, while MCT4 is more abundant in type II fibers (17). As a result, there is good agree- 
ment among alterations in muscle activity patterns, the levels of expression of MCT1 and MCT4, and the rates of lactate transport (15).

Phellinus linteus (PL) is a medicinal mushroom that has long been used to treat various diseases, such as tumors, gastroenteric disorders, inflammation, and lymphatic diseases $(23,24)$. PL is rich in polysaccharides and contains several aromatic compounds, including $p$-hydroxybenzaldehyde, caffeic acid, and hispidin, which can be isolated from cultured mycelia (23). Many studies have demonstrated that polysaccharides from PL are remarkably effective at inhibiting the growth of tumors without inducing severe toxic side effects (23, 25). The therapeutic effects of PL can be attributed to its ability to induce antioxidant enzyme activities, which suggests that some components of the PL preparation may afford protection against reactive oxygen species (26). In addition to immune modulating activity, $\beta$-glucan originating from PL is known to modulate inflammation $(27,28)$ and hyperplasia $(29)$. It is believed that polysaccharides and proteoglycans are responsible for the biological effects of these medicinal mushrooms, and there is an extensive body of literature regarding the immunologic response to $\beta$-glucans isolated from these medicinal mushrooms (30).

Many pharmacologic effects of PL have been reported; however, the effects of PL on endurance exercise in relation to central fatigue have not been clarified. Thus, this study was conducted to determine the effects of PL administration on serotonin expression in the dorsal raphe of the brain and on the expression of MCTs in gastrocnemius muscles during exhaustive exercise in rats.

\section{MATERIALS AND METHODS}

Plant material. The Phellinus linteus used in the experiments was obtained from the Kyung-Dong Market (Seoul, Korea). The plants were identified by Dr. E.H. Kim, a professor of Semyung University College of Oriental Medicine in Korea, and the voucher specimen was deposited at the herbarium of the Institute (NL0198).

Preparation of the aqueous extract of Phellinus linteus. To obtain the aqueous extract of PL, $300 \mathrm{~g}$ of PL was heat-extracted with distilled water, then concentrated with a rotary evaporator (Eyela, Tokyo, Japan). After being concentrated, the aqueous extract of PL was lyophilized and $10.9 \mathrm{~g}$ of powder was obtained. The fine powder of PL was then diluted in distilled water and passed through a $0.45-\mu \mathrm{m}$ syringe filter prior to use.

Animals and treatments. Male Sprague-Dawley rats weighing 200 $\pm 10 \mathrm{~g}$ ( $7 \mathrm{wk}$ old) were obtained from a commercial breeder (Daehan Biolink, Co., Chungbuk, Korea). All experimental procedures were performed in accordance with the animal care guidelines of the National Institutes of Health (NIH) and the Korean Academy of Medical Sciences. The animals were housed under laboratory conditions for $1 \mathrm{wk}$ prior to experiments under controlled temperature $\left(20 \pm 2^{\circ} \mathrm{C}\right)$ and light (07:00-19:00 h) conditions with food and water provided ad libitum.

The animals were equally divided into the following 6 groups ( $n=10$ in each group): control; exercise; exercise and $50 \mathrm{mg} / \mathrm{kg}$ of PL treatment; exercise and $100 \mathrm{mg} / \mathrm{kg}$ of PL treatment; exercise and $200 \mathrm{mg} / \mathrm{kg}$ of PL treatment; and exercise and caffeine treatment. The rats in the PL-treated groups received the indicated doses of aqueous extracts of PL orally once a day for $7 \mathrm{~d}$.

The treatment was administered $60 \mathrm{~min}$ prior to the start of exercise, which was conducted as described below. The rats in the control and exercise groups received normal saline and the rats in the caffeinetreated group received $100 \mathrm{mg} / \mathrm{kg}$ of caffeine orally once a day for $7 \mathrm{~d}$.

Treadmill exercise protocols. The physical exercise load applied in the present study consisted of running on a motor-driven treadmill without inclination. The rats in the exercise groups were forced to run on a treadmill for $30 \mathrm{~min}$ once a day during 6 consecutive days, whereas the rats in the control group were left on the treadmill without running for $30 \mathrm{~min}$. The exercise load consisted of forced running at a speed of $10 \mathrm{~m} / \mathrm{min}$ for $10 \mathrm{~min}$, followed by $16 \mathrm{~m} / \mathrm{min}$ for $10 \mathrm{~min}$, then $21 \mathrm{~m} / \mathrm{min}$ for the last $10 \mathrm{~min}$.

On the 7 th day of the experiments, the time to exhaustion during treadmill running was determined for the exercise groups. The time to exhaustion was defined as the time between the start of exercise and the first occurrence of failing to keep up with the treadmill for a period of $3 \mathrm{~min}$ or more. The speeds used for determination of the exhaustion time were $10 \mathrm{~m} / \mathrm{min}$ for $5 \mathrm{~min}$, followed by 16, 18, 21, 24, 26, 29, 32, 34, and $37 \mathrm{~m} / \mathrm{min}$ for $3 \mathrm{~min}$ each, then $40 \mathrm{~m} / \mathrm{min}$ until exhaustion, as described in a previous study (31).

Biochemical assays. Blood from each rat was collected by cardiac puncture and the serum was separated. The concentrations of total cholesterol, glucose, and triglycerides were estimated.

Brain preparation. The animals were sacrificed on the 7 th day of the experiments immediately after determination of the exhaustion time. One-half of the animals in each group were used for the brain preparation ( $n=5$ in each group). To prepare the brains, the animals were fully anesthetized with Zoletil $50^{\circledR}(10 \mathrm{mg} / \mathrm{kg}$, i.p.; Vibac, Carros, France), after which the rats were transcardially perfused with $50 \mathrm{~mm}$ phosphate-buffered saline (PBS), then fixed with a freshly prepared solution of $4 \%$ paraformaldehyde in $100 \mathrm{~mm}$ phosphate buffer (PB, pH 7.4). The brains were then removed, post-fixed in the same fixative overnight, and transferred into a $30 \%$ sucrose solution for cryoprotection. Coronal sections with a thickness of $40 \mu \mathrm{m}$ were made using a freezing microtome (Leica, Nussloch, Germany).

Immunohistochemistry for 5-HT and TPH. Immunohistochemistry was conducted to evaluate the 5-HT-positive and TPH-positive cells in the dorsal raphe. An average of 10 sections within the dorsal raphe region spanning from Bregma $-7.30 \mathrm{~mm}$ to $-8.00 \mathrm{~mm}$ were obtained from each brain. To begin the procedure, the sections were incubated in PBS for $10 \mathrm{~min}$, then 
washed 3 times in the same buffer. The sections were then incubated in $1 \%$ hydrogen peroxide $\left(\mathrm{H}_{2} \mathrm{O}_{2}\right)$ for $30 \mathrm{~min}$. Next, the sections were incubated overnight with rabbit anti-5-HT antibody (1 : 500; Immuno Star, Hudson, WI, USA) or mouse monoclonal anti-TPH antibody (1:1,000; Oncogene Research Products, Cambridge, UK). The sections were then incubated for $1 \mathrm{~h}$ with anti-rabbit secondary antibody (1:200; Vector Laboratories, Burlingame, CA, USA) for 5-HT immunohistochemistry or with anti-mouse secondary antibody (1:200; Vector Laboratories) for TPH immunohistochemistry. Next, the sections were incubated with avidin-biotin-peroxidase complex (1: 100; Vector Laboratories) for $1 \mathrm{~h}$ at room temperature. For staining, the sections were incubated in a solution consisting of $0.02 \% 3,3^{\prime}$-diaminobenzidine tetrahydrochloride $(\mathrm{DAB})$ and $0.03 \% \mathrm{H}_{2} \mathrm{O}_{2}$ in $50 \mathrm{~mm}$ Tris- $\mathrm{HCl}(\mathrm{pH} 7.6)$ for approximately $5 \mathrm{~min}$, after which they were then washed with PBS and mounted on gelatin-coated slides. The number of 5-HT- and TPH-positive cells was counted in the dorsal raphe of the selected sections using a light microscope (Olympus, Tokyo, Japan).

Western blot analysis. The remaining animals in each group were used for muscle preparation $(n=5$ in each group). The left gastrocnemius muscles were dissected on an ice-cold plate and subsequently homogenized in an ice-cold whole cell lysate buffer containing $50 \mathrm{mM}$ HEPES (pH 7.5), $150 \mathrm{mM} \mathrm{NaCl}, 10 \%$ glycerol, $1 \%$ Triton X-100, $1.5 \mathrm{~mm}$ magnesium chloride hexahydrate, $1 \mathrm{mM}$ ethyleneglycol-bis-( $\beta$-aminoethyl ether)$N, N^{\prime}$-tetraacetic acid (EGTA), $1 \mathrm{mM}$ phenylmethylsulfonyl fluoride (PMSF), $2 \mu \mathrm{g} / \mathrm{mL}$ leupeptin, $1 \mu \mathrm{g} / \mathrm{mL}$ pepstatin, $1 \mathrm{~mm}$ sodium ortho vanadate, and $100 \mathrm{~mm}$ sodium fluoride, after which the mixture was incubated on ice for $30 \mathrm{~min}$. The mixture was then centrifuged at $14,000 \times g$ for $15 \mathrm{~min}$ at $4^{\circ} \mathrm{C}$. The supernatants were then used to analyze the expression of the MCT1 and MCT4 proteins. The protein concentration was measured using a Bio-Rad colorimetric protein assay kit (Bio-Rad, Hercules, CA, USA). Next, $40 \mu \mathrm{g}$ of protein were separated on SDS-polyacrylamide gels and transferred onto a nitrocellulose membrane (Schleicher and Schuell GmbH, Dassel, Germany). Goat MCT1 ( 1 : 1,000; Santa Cruz Biotechnology, Inc., Santa Cruz, CA, USA) and rabbit MCT4 antibodies (1 : 1,000; Santa Cruz Biotechnology, Inc.) were used as primary antibodies. In addition, horseradish peroxidase-conjugated anti-goat antibody against MCT4 (1 : 4,000; Santa Cruz Biotechnology, Inc.) was used to probe for MCT1, while anti-rabbit antibody ( 1 : 2,000; Santa Cruz Biotechnology, Inc.) was used as a secondary antibody. Band detection was performed using an enhanced chemiluminescence (ECL) detection system (Santa Cruz Biotechnology, Inc.).

Statistical analysis. The results are presented as the mean \pm the standard error (SE). The data were analyzed by one-way analysis of variance (ANOVA), followed by Duncan's post-hoc test using SPSS. Differences were considered significant at a $p<0.05$.

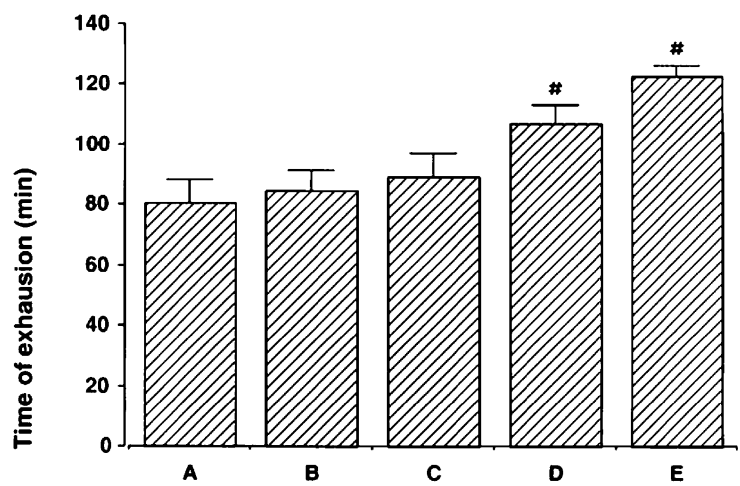

Fig. 1. The treadmill running time to exhaustion in response to treatment with different doses of Phellinus linteus (PL). A: exercise group, B: exercise and $50 \mathrm{mg} /$ $\mathrm{kg}$ of PL-treated group, C: exercise and $100 \mathrm{mg} / \mathrm{kg}$ of PL-treated group, D: exercise and of $200 \mathrm{mg} / \mathrm{kg}$ PLtreated group, E: exercise and caffeine-treated group. ${ }^{\#} p<0.05$ when compared to the exercise group. Values shown represent the mean $\pm \mathrm{SE}$.

Table 1. Serum concentrations of total cholesterol, glucose, triglyceride $(\mathrm{mg} / \mathrm{dL})$.

\begin{tabular}{cllc}
\hline Group Total cholesterol & \multicolumn{1}{c}{ Glucose } & Triglyceride \\
\hline A & $47.62 \pm 2.78$ & $202.62 \pm 29.47$ & $132.25 \pm 16.69$ \\
B & $48.50 \pm 2.19$ & $183.87 \pm 8.63$ & $60.37 \pm 6.52^{*}$ \\
C & $55.42 \pm 5.12$ & $171.42 \pm 16.63$ & $40.80 \pm 7.62^{*, \#}$ \\
D & $67.42 \pm 5.47^{*, \#}$ & $148.71 \pm 12.94^{*, \#}$ & $20.14 \pm 5.96^{*, \#}$ \\
E & $64.57 \pm 4.73^{*, \#}$ & $108.57 \pm 14.85^{*, \#}$ & $11.14 \pm 3.16^{*, \#}$ \\
\hline
\end{tabular}

A: control group, B: exercise group, C: exercise and $50 \mathrm{mg} / \mathrm{kg}$ Phellinus linteus (PL)-treated group, D: exercise and $100 \mathrm{mg} / \mathrm{kg}$ PL-treated group, E: exercise and $200 \mathrm{mg} / \mathrm{kg}$ PL-treated group. ${ }^{*} p<0.05$ when compared to the control group. ${ }^{\#} p<0.05$ when compared to the exercise group. Values shown represent the mean \pm SE.

\section{RESULTS}

Effect of Phellinus linteus on the time to exhaustion during treadmill running

The effects of PL on the time to exhaustion are presented in Fig. 1. These findings indicate that the time to exhaustion in response to treadmill running was increased in response to PL treatment. Specifically, treatment with PL at $200 \mathrm{mg} / \mathrm{kg}$ and caffeine at $100 \mathrm{mg} / \mathrm{kg}$ statistical significantly increased the time to exhaustion by treadmill running when compared to the exercise group $(p<0.05)$. The results show that PL was just as effective as caffeine for increasing the time to exhaustion by treadmill running.

Effect of Phellinus linteus on total cholesterol, glucose, and triglyceride concentrations

The effects of PL on serum total cholesterol, glucose, and triglyceride concentrations are presented in Table 1. The serum total cholesterol was significantly increased by treatment with PL compared to the exercise group $(p<0.05)$. However, the serum glucose and triglycerides were significantly decreased by treatment 

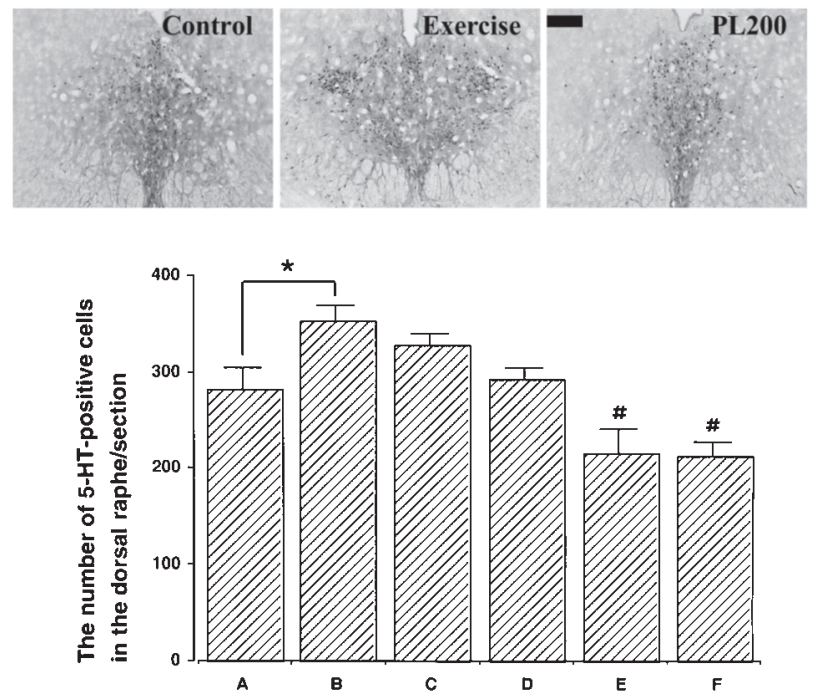

Fig. 2. Dose-dependent effect of Phellinus linteus (PL) on 5-hydroxytryptamine (5-HT) expression in the dorsal raphe. (Upper) Photomicrographs of 5-HT-positive cells in the dorsal raphe. The scale bar represents $250 \mu \mathrm{m}$. (Lower) Number of 5-HT-positive cells in the dorsal raphe in each group. A: control group, B: exercise group, C: exercise and $50 \mathrm{mg} / \mathrm{kg}$ of PL-treated group, D: exercise and $100 \mathrm{mg} / \mathrm{kg}$ of PL-treated group, E: exercise and $200 \mathrm{mg} / \mathrm{kg}$ of PL-treated group, F: exercise and caffeine-treated group. ${ }^{*} p<0.05$ when compared to the control group. ${ }^{\#} p<0.05$ when compared to the exercise group. Values shown represent the mean \pm SE.
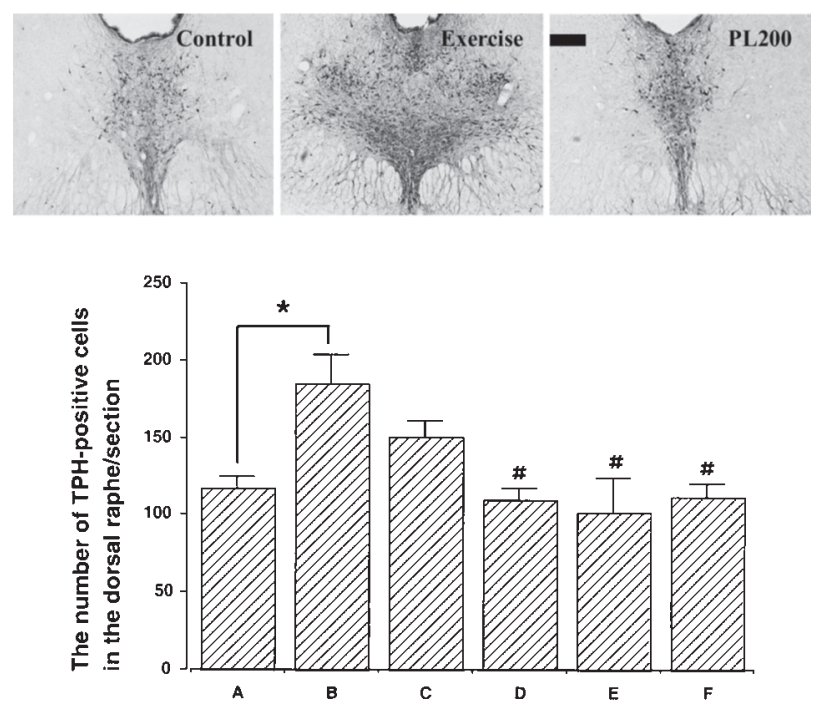

Fig. 3. Dose-dependent effect of Phellinus linteus (PL) on tryptophan hydroxylase (TPH) expression in the dorsal raphe. (Upper) Photomicrographs of TPH-positive cells in the dorsal raphe. The scale bar represents $250 \mu \mathrm{m}$. (Lower) Number of TPH-positive cells in the dorsal raphe in each group. A: control group, B: exercise group, C: exercise and $50 \mathrm{mg} / \mathrm{kg}$ of PL-treated group, D: exercise and $100 \mathrm{mg} / \mathrm{kg}$ of PL-treated group, E: Exercise and $200 \mathrm{mg} / \mathrm{kg}$ of PL-treated group, F: exercise and caffeine-treated group. ${ }^{*} p<0.05$ when compared to the control group. ${ }^{\#} p<0.05$ when compared to the exercise group. Values shown represent the mean \pm SE.
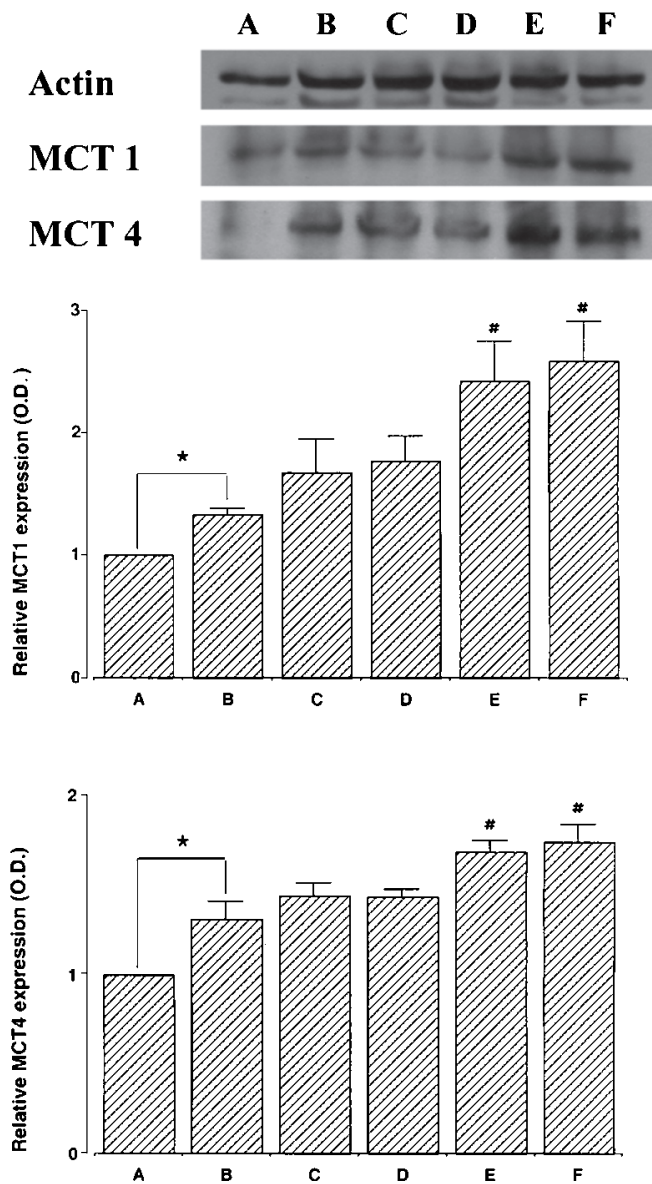

Fig. 4. Results of Western blot analysis of the protein levels of monocarboxylate transporter 1 and 4 . A: control group, B: exercise group, C: exercise and $50 \mathrm{mg} / \mathrm{kg}$ of Phellinus linteus (PL)-treated group, D: exercise and $100 \mathrm{mg} / \mathrm{kg}$ of PL-treated group, E: exercise and $200 \mathrm{mg} / \mathrm{kg}$ of PL-treated group, F: exercise and caffeine-treated group. Actin was used as the internal control. ${ }^{*} p<0.05$ when compared to the control group. ${ }^{\#} p<0.05$ when compared to the exercise group. Values shown represent the mean \pm SE.

with PL compared to the exercise group $(p<0.05)$.

Effect of Phellinus linteus on 5-HT expression in the dorsal raphe

Photomicrographs of 5-HT-positive cells in the dorsal raphe are presented in Fig. 2. These results demonstrate that treadmill exercise led to increased synthesis of 5HT in the dorsal raphe $(p<0.05)$ and that PL-treatment suppressed the exercise-induced 5-HT synthesis. Specifically, treatment with PL at $200 \mathrm{mg} / \mathrm{kg}$ and with caffeine at $100 \mathrm{mg} / \mathrm{kg}$ statistical significantly suppressed 5-HT synthesis in the dorsal raphe when compared to the exercise group $(p<0.05)$.

Effect of Phellinus linteus on TPH expression in the dorsal raphe

Photomicrographs of TPH-positive cells in the dorsal raphe are presented in Fig. 3. These results demonstrate that treadmill exercise increased the expression of TPH in the dorsal raphe $(p<0.05)$ and that PL treatment suppressed exercise-induced TPH expression. Specifically, treatment with PL at 100 and $200 \mathrm{mg} / \mathrm{kg}$ and caf- 
feine at $100 \mathrm{mg} / \mathrm{kg}$ statistical significantly suppressed TPH expression in the dorsal raphe when compared to the exercise group $(p<0.05)$.

Effect of Phellinus linteus on MCT1 and MCT4 expression in gastrocnemius muscles

The expression of MCT1 and MCT4 protein was analyzed to provide an estimate of the relative level of expression. In the present study, the expression of MCT1 and MCT4 protein in the control was set at 1.00 (Fig. 4).

These results demonstrate that treadmill exercise increased the expression of MCT1 and MCT4 in the gastrocnemius muscle $(p<0.05)$, and that treatment with PL led to an increase in exercise-induced MCT1 and MCT4 expression. Specifically, treatment with PL at $200 \mathrm{mg} / \mathrm{kg}$ and caffeine at $100 \mathrm{mg} / \mathrm{kg}$ statistical significantly increased MCT1 and MCT4 expression in the gastrocnemius muscles when compared to the exercise group $(p<0.05)$.

\section{DISCUSSION}

In the present study, the effect of PL on exhaustion time was determined using rats. The time to exhaustion in response to treadmill running was significantly prolonged in response to treatment with $200 \mathrm{mg} / \mathrm{kg}$ PL or $100 \mathrm{mg} / \mathrm{kg}$ caffeine. Ingestion of caffeine is known to increase endurance performance, particularly during prolonged periods of exercise (32-34). Indeed, caffeine may play an ergogenic role in exercise performance by altering both neural perception of effort and substrate availability (35). The ergogenic action of caffeine has been well-documented (12, 32-34), and administration of caffeine increased the exhaustion time by treadmill running in the current study. Caffeine has an issue with respect to doping tests. In addition, a high concentration of caffeine is known to induce many medical problems. Developing new ergogenic aids free from doping tests is an important strategy for athletes (36). In the present study, treatment with PL increased a running time similar to caffeine. Based on our previous studies, we tried to identify herbs, including PL, which can be developed as new ergogenic aids without the complications associated with caffeine.

Physical fatigue is defined as the inability to continue exercise performance (37-39). The mechanisms of fatigue during exercise are not yet clear. Muscle fiber composition, physical fitness, and the intensity, type, and duration of the muscle contraction, are related to physical fatigue (40). The rapid depletion of glycogen and glucose stores $(41,42)$, the accumulation of catabolites, such as lactate (43), the expression of brain serotonin $(44,45)$, the increase in $\mathrm{H}^{+}$and intracellular $\mathrm{Pi}$ (46-50), increased oxygen consumption causing oxidative stress and tissue damage $(41,51,52)$, and failure of $\mathrm{Ca}^{2+}$ release by the sarcoplasmic reticulum $(53,54)$ have been suggested as underlying factors inducing physical fatigue. These factors, alone or in combination, seem to diminish the ability to perform exercise.

Our research on the central fatigue hypothesis is that over-expression of the level of serotonin in the brain induced by exhaustive exercise disturbs exercise performance. It is possible that exercise performance can be continued if the level of serotonin in the brain is suppressed. As shown in this study, PL and caffeine suppressed serotonin expression in the brain with a corresponding increase in exhaustive running time. These results suggest that $\mathrm{PL}$ and caffeine overcame central fatigue, and then extended the time of treadmill running.

We also evaluated the peripheral factors concerned with stopping exercise. As shown in Table 1, the serum cholesterol concentration was not matched with the running time (distance). The serum glucose and triglycerides concentrations were decreased in relation with running time. These results showed that long-term exercise depleted the levels of glucose and triglycerides; however, these data did not show that depletion of glucose or triglycerides is the main factor underlying fatigue-induced cessation of exercise.

To elucidate the ergogenic mechanism of PL, we evaluated the serotonin levels in the dorsal raphe. Most of the cell bodies of the serotonergic neurons in the brain arise from the dorsal raphe nuclei, which send projections to diverse target regions, such as the limbic system, hypothalamus, striatum, and cerebral cortex (8). The central fatigue hypothesis states that increases in the concentration of 5 -HT in the brain during prolonged exercise impairs CNS function, thereby inducing a deterioration of exercise performance (55). An increase in 5-HT depends on the exercise types or the endurance running capacity. Wheel running significantly elevates 5 -HT $1 \mathrm{~A}$ autoreceptor mRNA in the dorsal raphe compared to sedentary controls $(56,57)$. A number of experiments support the hypothesis that constraints of the 5-HT system during physical activity could be involved in the onset of exercise-induced fatigue observed in animals (58). It has also been suggested that an increase or decrease in 5-HT activity in the brain during prolonged exercise hastens or delays the onset of fatigue, respectively (59), while blocking 5HT activity delays the onset time of fatigue $(6,60)$. Furthermore, there are indications that increased 5-HT concentrations in the brain and the overall serotonergic activity that occur during endurance exercise play a role in physical and mental fatigue (61). TPH was not saturated under normal physiologic conditions (62); a change in rate-limiting TPH2 availability in the presence of adequate substrate (i.e., tryptophan) could potentially alter the amount of 5-HT synthesized during physical activity. Increased TPH mRNA expression is a good predictor of increased TPH activity, which leads to enhanced 5-HT synthesis (63). Fatigue during prolonged exercise may be influenced by the activity of the brain serotonergic system, and this is referred as the "central fatigue hypothesis" (64). It has been suggested that elevated central tryptophan availability increases 5-HT activity during prolonged exercise, which causes fatigue by increasing lethargy and loss of central motivation $(64,65)$.

Several studies have demonstrated that excessive 
exercise increases TPH-immunoreactivity and 5-HT synthesis in the dorsal raphe of rats, which in turn leads to exhaustion during running $(11,12,66-68)$. Treatment with Red ginseng and Acanthopanax senticosus $(100 \mathrm{mg} / \mathrm{kg}$ for each) inhibits the exercise-induced increase in the number of 5-HT- and TPH-positive cells in the dorsal raphe $(68,69)$. Treatment with Paeonia radix $(50 \mathrm{mg} / \mathrm{kg})$ reduces fatigue, both during exercise and at rest, through inhibition of 5-HT synthesis and TPH expression (11). Acanthopanax senticosus contains an abundance of organic compounds. Chlorogenic acid (CHA) and syringaresinol di- $O$ - $\beta$-D-glucoside (SYG) are the main components of the Acanthopanax senticosus $(70,71)$. SYG was suggested as the main compound exerting a pharmacologic effect on swimming time in rats (70). Saponin is the main component of Ginseng radix. Ginsenosides are known to have an anti-stress effect and attenuate neuronal cell damage induced by glutamate and kainic acid: ginsenosides Rb1 and Rg3 protect neurons against excitotoxicity and oxidative stress (72). Paeonia radix contains a multitude of complex organic compounds. Paeoniflorin, one of the compounds extracted from Paeonia radix, is known to have anti-inflammatory and anti-stress effects, and decreases blood pressure (73). All of these above-mentioned herbs, including PL, increase the time to exhaustion through inhibition of serotonin production in the brain. These suppressing effects of PL appear at higher doses compared to Red ginseng, Acanthopanax senticosus, and Paeonia radix. The ergogenic action of PL is not as potent; however, the polysaccharides and aromatic compounds in PL exert antitumor and antioxidant activities $(23,25)$. Our previous results showed that any substances, one substance or the combined action of several substances, from these herbs may exert ergogenic actions, although they have not been clarified.

In the present study, exhaustive treadmill exercise led to increased 5-HT synthesis and TPH expression in the dorsal raphe, but treatment with PL attenuated these effects. The most potent inhibition of PL on 5-HT synthesis and TPH expression was observed in response to treatment with $200 \mathrm{mg} / \mathrm{kg}$. We also compared the effects of PL on the synthesis of 5-HT and the expression of TPH with the effects of caffeine. Treatment with PL at a dose of $200 \mathrm{mg} / \mathrm{kg}$ and treatment with caffeine at $100 \mathrm{mg} / \mathrm{kg}$ were equally effective at suppressing 5-HT synthesis and TPH expression in the dorsal raphe. A reduction in TPH activity in vivo rapidly leads to a decrease in the release of 5-HT (74), indicating that TPH can profoundly influence the synaptic function of 5-HT. The present results suggest that the time to exhaustion was increased through a decrease in 5-HT synthesis and TPH expression in the dorsal raphe.

Thomas et al. (75) demonstrated that increased levels of MCT1 in human skeletal muscles were associated with an improved ability to remove blood lactate and fatigue resistance following a single bout of all-out exercise. An increase in MCT1 was demonstrated $2 \mathrm{~h}$ after exhaustive running, which may be indicative of increased lactate removal (76). It has also been sug- gested that increased MCT1 protein content was associated with training-induced improvement of lactate shuttling $(77,78)$. The extent of adaptation of MCT1 and MCT4 expression to exercise was related to the intensity of training (20). Taken together, these isoform-specific differences suggest that lactate is primarily taken up into the muscle cells via MCT1, whereas MCT4 is involved in the removal of lactate so that oxidation can occur in inactive muscle fibers $(16,20,77)$.

In the present study, treadmill exercise led to increased MCT1 and MCT4 expression in the gastrocnemius muscles, and treatment with $200 \mathrm{mg} / \mathrm{kg}$ PL further enhanced the expression of MCT1 and MCT4 when compared with the untreated exercise group. The rats treated with caffeine (the positive control group) also showed an increase in MCT1 and MCT4 expression compared to the untreated exercise group. Gastrocnemius muscle has both type I and type II fibers (e.g., red and white gastrocnemius; 79, 80). White and red muscles were not separated in the current experiments; however, we analyzed the effects of PL on MCT1 and MCT4 expression in the mixed fiber gastrocnemius muscles. It is possible that the exhaustion exercise applied in this study was sufficient to induce an increase in the expression of MCT1 and MCT4 protein. An increase in lactate transport capacity was also reported following exhaustive exercise $(81,82)$. It has previously been reported that the rate of lactate flux into and out of the muscles is correlated with the content of MCT1 and MCT4 in the muscles $(19,20,83)$. Chronic skeletal muscle activity is also known to have a strong influence on the expression of MCTs. Additionally, inactivity has been shown to reduce the expression of MCT1 and MCT4 (21), while training increased the expression $(17,84)$. Thus, the increase in MCT1 and MCT4 in response to PL treatment indicates that PL may possess the ability to increase the rate of lactate removal from cells.

In the present study, PL treatment led to increased endurance exercise performance via the inhibition of 5HT synthesis and TPH expression in the dorsal raphe. The treatment with caffeine also decreased 5-HT synthesis and TPH expression compared to the untreated exercise group. These results suggest that PL effectively suppresses endurance exercise-induced central fatigue through inhibition of serotonin production in the brain. PL also enhanced the expression of MCT1 and MCT4 in gastrocnemius muscles, which suggests that PL is effective at suppressing endurance exercise-induced peripheral fatigue through increased lactate removal in the muscles. In this study, we verified the effect of treatment of PL or caffeine for $7 \mathrm{~d}$. The present results were obtained from repeated administration of PL in rats with cumulative training. However, there is a possibility that a single treatment with PL might exert similar results. Additional studies are needed to verify the acute effectiveness of PL. Nevertheless, the results of this study clearly demonstrate that PL exerts an ergogenic effect. 


\section{Acknowledgments}

This work was supported by the Korea Research Foundation Grant funded by the Korean Government (MOEHRD, Basic Research Promotion Fund) (KRF2008-355-G00017).

\section{REFERENCES}

1) Bonham AC. 1995. Neurotransmitters in the CNS control of breathing. Respir Physiol 101: 219-230.

2) Richerson GB. 2004. Serotonergic neurons as carbon dioxide sensors that maintain $\mathrm{pH}$ homeostasis. Nat Rev Neurosci 5: 449-461.

3) Veenstra-VanderWeele J, Anderson GM, Cook EH Jr. 2000. Pharmacogenetics and the serotonin system: initial studies and future directions. Eur J Pharmacol 410: 165-181.

4) Fitzpatrick PF. 1999. Tetrahydropterin-dependent amino acid hydroxylases. Annu Rev Biochem 68: 355381.

5) Boldrini M, Underwood MD, Mann JJ, Arango V. 2005. More tryptophan hydroxylase in the brainstem dorsal raphe nucleus in depressed suicides. Brain Res 1041: 19-28.

6) Bailey SP, Davis JM, Ahlborn EN. 1993. Neuroendocrine and substrate responses to altered brain 5-HT activity during prolonged exercise to fatigue. J Appl Physiol 74: 3006-3012.

7) Chaouloff F, Elghozi J, Guezennec YL, Laude D. 1985. Effects of conditioned running on plasma, liver and brain tryptophan and on brain 5-hydroxytryptamine metabolism of the rat. Br J Pharmacol 86: 33-41.

8) Jacobs BL, Azmitia EC. 1992. Structure and function of brain serotonin system. Physiol Rev 72: 165-229.

9) Spampinato U, Esposito E, Samamin R. 1985. Serotonin agonists reduce dopamine synthesis in the striatum only when the impulse flow of nigro striatal neurons is intact. J Neurochem 45: 980-982.

10) Dwyer D, Flynn J. 2002. Short term aerobic exercise training in young males does not alter sensitivity to a central serotonin agonist. Exp Physiol 87: 83-89.

11) Hong JA, Chung SH, Lee JS, Kim SS, Shin HD, Kim H, Jang MH, Lee TH, Lim BV, Kim YP, Kim CJ. 2003. Effects of Paeonia radix on 5-hydroxytryptamine synthesis and tryptophan hydroxylase expression in the dorsal raphe of exercised rats. Biol Pharm Bull 26: 166-169.

12) Lim BV, Jang MH, Shin MC, Kim HB, Kim YJ, Kim YP, Chung JH, Kim H, Shin MS, Kim SS, Kim EH, Kim CJ. 2001. Caffeine inhibits exercise-induced increase in tryptophan hydroxylase expression in dorsal and median raphe of Sprague-Dawley rats. Neurosci Lett 308: $25-28$.

13) Halestrap AP, Price NT. 1999. The proton-linked monocarboxylate transporter (MCT) family: structure, function and regulation. Biochem J 343: 281-299.

14) Halestrap AP, Meredith D. 2004. The SLC16 gene family from monocarboxylate transporters (MCTs) to aromatic amino acid transporters and beyond. Pflügers Arch 447: 619-628.

15) Enoki T, Yoshida Y, Lally J, Hatta H, Bonen A. 2006. Testosterone increases lactate transport, monocarboxylate transporter (MCT) 1 and MCT4 in rat skeletal muscle. J Physiol 577: 433-443.

16) Bonen A. 2001. Expression of lactate transporters (MCT1, MCT4) in heart and muscle. Eur J Appl Physiol 86: $6-11$.
17) Pilegaard H, Terzis G, Halestrap A, Juel C. 1999. Distribution of the lactate $/ \mathrm{H}^{+}$transporter isoforms MCT1 and MCT4 in human skeletal muscle. Am J Physiol Endocrinol Metab 276: E843-E848.

18) Juel C, Halestrap AP. 1999. Lactate transport in skeletal muscle-role and regulation of the monocarboxylate transporter. J Physiol 517: 633-642.

19) McCullagh KJ, Poole RC, Halestrap AP, O’Brien M, Bonen A. 1996. Role of the lactate transporter (MCT1) in skeletal muscles. Am J Physiol Endocrinol Metab 271: E143-E150.

20) Bonen A, Tonouchi M, Miskovic D, Heddle C, Heikkila JJ, Halestrap AP. 2000. Isoform-specific regulation of the lactate transporters MCT1 and MCT4 by contractile activity. Am J Physiol Endocrinol Metab 279: E1131E1138.

21) Wilson MC, Jackson VN, Heddle C, Price NT, Pilegaard H, Juel C, Bonen A, Montgomery I, Hutter OF, Halestrap AP. 1998. Lactic acid efflux from white skeletal muscle is catalyzed by the monocarboxylate transporter isoform MCT3. J Biol Chem 273: 15920-15926.

22) Yoshida $Y$, Hatta H, Kato M, Enoki T, Kato H, Bonen A. 2004. Relationship between skeletal muscle MCT1 and accumulated exercise during voluntary wheel running. J Appl Physiol 97: 527-534.

23) Han SB, Lee CW, Jeon YJ, Hong ND, Yoo ID, Yang KH, Kim HM. 1999. The inhibitory effect of polysaccharides isolated from Phellinus linteus on tumor growth and metastasis. Immunopharmacology 41: 157-164.

24) Sohn EH, Roh HS, Park YS, Sohn ES, Kang SC, Kang NS, Pyo S. 2008. Phellinus linteus; Market and technology trends analysis. Kor J Biotechnol Bioeng 23: 109-117.

25) Borchers AT, Stern JS, Hackman RM, Keen CL, Gershwin ME. 1999. Mushrooms, tumors, and immunity. Proc Soc Exp Biol Med 221: 281-293.

26) Song YS, Kim SH, Sa JH, Jin C, Lim CJ, Park EH. 2003. Antiangiogenic, antioxidant and xanthine oxidase inhibition activities of the mushroom Phellinus linteus. J Ethnopharmacol 88: 113-116.

27) Kim SH, Song YS, Kim SK, Kim BC, Lim CJ, Park EH. 2004. Anti-inflammatory and related pharmacological activities of the $n$-BuOH subfraction of mushroom Phellinus linteus. J Ethnopharmacol 93: 141-146.

28) Inagaki N, Shibata T, Itoh T, Suzuki T, Tanaka H, Nakamura T, Akiyama Y, Kawagishi H, Nagai H. 2005. Inhibition of IgE-dependent mouse triphasic cutaneous reaction by a boiling water fraction separated from mycelium of Phellinus linteus. Evid Based Complement Alternat Med 2: 369-374.

29) Shibata Y, Kashiwagi B, Arai S, Fukabori Y, Suzuki K. 2005. Administration of extract of mushroom Phellinus linteus induces prostate enlargement with increase in stromal component in experimentally developed rat model of benign prostatic hyperplasia. Urology 66: 455-460.

30) Zaidman BZ, Tassin M, Mahajna J, Wasser SP. 2005. Medicinal mushroom modulators of molecular targets as cancer therapeutics. Appl Microbiol 67: 453-468.

31) Lee MK, Lim HH, Song YK, Ko IG, Kim H, Shin MS, Lee TH, Kim CJ, Joo KJ, Choi HH, Park JK, Lim BV. 2006. Effect of the mixture of Red Ginseng and Paenia Radix on the treadmill running and swimming exercise in rats. Kore J Exer Nutr 10: 255-263.

32) Graham TE, Hibbert E, Sathasivam P. 1998. Metabolic and exercise endurance effects of coffee and caffeine 
ingestion. J Appl Physiol 85: 883-889.

33) Graham TE, Rush JWE, van Soeren MH. 1994. Caffeine and exercise: metabolism and performance. Can J Appl Physiol 19: 111-138.

34) Tarnopolsky MA. 1994. Caffeine and endurance performance. Sports Med 18: 109-125.

35) Cole KJ, Costill DL, Starling RD, Goodpaster BH, Trappe SW, Fink WJ. 1996. Effect of caffeine ingestion on perception of effort and subsequent work production. Int $J$ Sport Nutr 6: 14-23.

36) Burke LM. 2008. Caffeine and sports performance. Appl Physiol Nutr Metab 33: 1319-1334.

37) Gandevia SC. 1992. Some central and peripheral factors affecting human motoneuronal output in neuromuscular fatigue. Sports Med 13: 93-98.

38) Hagberg M. 1981. Muscular endurance and surface electromyogram in isometric and dynamic exercise. $J$ Appl Physiol 51: 1-7.

39) Hawley JA, Reilly T. 1997. Fatigue revisited. J Sports Sci 15: $245-246$.

40) Millet GY, Lepers R. 2004. Alterations of neuromuscular function after prolonged running, cycling and skiing exercises. Sports Med 34: 105-116.

41) Brooks GA. 1998. Mammalian fuel utilization during sustained exercise. Comp Biochem Physiol B Biochem Mol Biol 120: 89-107.

42) Hargreaves M. 1997. Interactions between muscle glycogen and blood glucose during exercise. Exerc Sport Sci Rev 25: 21-39.

43) Lindinger MI, McKelvie RS, Heigenhauser GJ. 1995. K+ and Lac-distribution in humans during and after highintensity exercise: role in muscle fatigue attenuation? J Appl Physiol 78: 765-777.

44) Gartside SE, Cowen PJ, Sharp T. 1992. Evidence that the large neutral amino acid L-valine decreases electricallyevoked release of 5-HT in rat hippocampus in vivo. Psychopharmacology 109: 251-253.

45) Davis JM, Bailey SP. 1997. Possible mechanisms of central nervous system fatigue during exercise. Med Sci Sports Exerc 29: 45-57.

46) Giannesini B, Cozzone PJ, Bendahan D. 2003. Noninvasive investigations of muscular fatigue: metabolic and electromyographic components. Biochimie 85: 873-883.

47) McLester JR. 1997. Muscle contraction and fatigue. The role of adenosine $5^{\prime}$-diphosphate and inorganic phosphate. Sports Med 23: 287-305.

48) Sahlin K, Tonkonogi M, Soderlund K. 1998. Energy supply and muscle fatigue in humans. Acta Physiol Scand 162: 261-266.

49) Stackhouse SK, Reisman DS, Binder-Macleod SA. 2001. Challenging the role of $\mathrm{pH}$ in skeletal muscle fatigue. Phys Ther 81: 1897-1903.

50) Westerblad H, Allen DG, Lannergren J. 2002. Muscle fatigue: lactic acid or inorganic phosphate the major cause? News Physiol Sci 17: 17-21.

51) Alessio HM. 1993. Exercise-induced oxidative stress. Med Sci Sports Exerc 25: 218-224.

52) Liu J, Yeo HC, Overvik-Douki E, Hagen T, Doniger SJ, Chu DW, Brooks GA, Ames BN. 2000. Chronically and acutely exercised rats: biomarkers of oxidative stress and endogenous antioxidants. J Appl Physiol 89: 21-28.

53) Allen DG. 2004. Skeletal muscle function: role of ionic changes in fatigue, damage and disease. Clin Exp Pharmacol Physiol 31: 485-493.
54) Green HJ. 1997. Mechanisms of muscle fatigue in intense exercise. J Sports Sci 15: 247-256.

55) Newsholme EA, Blomstrand E, Ekblom B. 1992. Physical and mental fatigue: metabolic mechanisms and importance of plasma amino acids. Br Med Bull 48: 477-495.

56) Greenwood BN, Foley TE, Day HE, Burhans D, Brooks L, Campeau S, Fleshner M. 2005. Wheel running alters serotonin (5-HT) transporter, 5-HT(1A), 5-HT(1B), and alpha(1b)-adrenergic receptor mRNA in the rat raphe nuclei. Biol Psychiat 57: 559-568.

57) Greenwood BN, Foley TE, Day HE, Campisi J, Hammack SH, Campeau S, Maier SF, Fleshner M. 2003. Freewheel running prevents learned helplessness/behavioral depression: role of dorsal raphe serotonergic neurons. $J$ Neurosci 23: 2889-2898.

58) Foley TE, Greenwood BN, Day HE, Koch LG, Britton SL, Fleshner M. 2006. Elevated central monoamine receptor mRNA in rats bred for high endurance capacity: implications for central fatigue. Behav Brain Res 174: 132-142.

59) Davis JM, Bailey SP. 1997. Possible mechanisms of central nervous system fatigue during exercise. Med Sci Sports Exerc 29: 45-57.

60) Ahlenius S, Kaur P, Salmi P. 1997. Biphasic effects of 8OH-DPAT on endurance of treadmill performance in the male rat. Eur Neuropsychopharmacol 7: 89-94.

61) Davis JM, Alderson NL, Welsh RS. 2000. Serotonin and central nervous system fatigue: nutritional considerations. Am J Clin Nutr 72: 573S-578S.

62) Friedman PA, Kappelman AH, Kaufman S. 1972. Partial purification and characterization of tryptophan hydroxylase from rabbit hindbrain. J Biol Chem 247: 4165-4173.

63) Chamas F, Serova L, Sabban EL. 1999. Tryptophan hydroxylase mRNA levels are elevated by repeated immobilization stress in rat raphe nuclei but not in pineal gland. Neurosci Lett 267: 157-160.

64) Newsholme EA, Blomstrand E, Ekblom B. 1992. Physical and mental fatigue: metabolic mechanisms and importance of plasma amino acids. Br Med Bull $\mathbf{4 8}$ : 477-495.

65) Soares DD, Coimbra CC, Marubayashi U. 2007. Tryptophan-induced central fatigue in exercising rats is related to serotonin content in preoptic area. Neurosci Lett 415: 274-278.

66) Foley TE, Greenwood BN, Day HE, Koch LG, Britton SL, Fleshner M. 2006. Elevated central monoamine receptor mRNA in rats bred for high endurance capacity: implications for central fatigue. Behav Brain Res 174: 132-142.

67) Lee SH, Chung SH, Lee JS, Kim SS, Shin HD, Lim BV, Jang MH, Kim H, Kim EH, Kim CJ. 2002. Effects of acupuncture on the 5-hydroxytryptamine synthesis and tryptophan hydroxylase expression in the dorsal raphe of exercised rats. Neurosci Lett 332: 17-20.

68) Min YK, Chung SH, Lee JS, Kim SS, Shin HD, Lim BV, Shin MC, Jang MH, Kim EH, Kim CJ. 2003. Red ginseng inhibits exercise-induced increase in 5-hydroxytryptamine synthesis and tryptophan hydroxylase expression in dorsal raphe of rats. J Pharmacol Sci 93: 218-221.

69) Rhim YT, Kim H, Yoon SJ, Kim SS, Chang HK, Lee TH, Lee HH, Shin MC, Shin MS, Kim CJ. 2007. Effect of Acanthopanax senticosus on 5-hydroxytryptamine syn- 
thesis and tryptophan hydroxylase expression in the dorsal raphe of exercised rats. J Ethnopharmacol 114: 38-43.

70) Nishibe S, Kinoshita H, Takeda H, Okano G. 1990. Phenolic compounds from stem bark of Acanthopanax senticosus and their pharmacological effect in chronic swimming stressed rats. Chem Pharm Bull 38: 1763-1765.

71) Fujikawa T, Yamaguchi A, Morita I, Takeda H, Nishibe S. 1996. Protective effects of Acanthopanax senticosus Harms from Hokkaido and its components on gastric ulcer in restrained cold water stressed rats. Biol Pharm Bull 19: 1227-1230.

72) Kim YC, Kim SR, Markelonis GJ, Oh TH. 1998. Ginsenosides $\mathrm{Rb} 1$ and $\mathrm{Rg} 3$ protect cultured rat cortical cells from glutamate induced neurodegeneration. J Neurosci Res 53: 426-432.

73) Egger K, Keil M. 1969. Flavone glycosides in the flowers of Paeonia arborea, P. suffruicosa. Planta 88: 154-156.

74) Gartside SE, Cowen PJ, Sharp T. 1992. Evidence that the large neutral amino acid L-valine decreases electrically evoked release of 5-HT in rat hippocampus in vivo. Psychopharmacology 109: 251-253.

75) Thomas C, Sirvent P, Perrey S, Raynaud E, Mercier J. 2004. Relationships between maximal muscle oxidative capacity and blood lactate removal after supramaximal exercise and fatigue indexes in humans. J Appl Physiol 97: 2132-2138.

76) Thomas C, Perrey S, Lambert K, Hugon G, Mornet D, Mercier J. 2005. Monocarboxylate transporters, blood lactate removal after supramaximal exercise, and fatigue indexes in humans. J Appl Physiol 98: 804-809.

77) Brooks GA, Brown MA, Butz CA, Sicurello JP, DuBouchaud H. 1999. Cardiac and skeletal muscle mitochondria have a monocarboxylate transporter MCT1. J Appl Physiol 87: 1713-1718.

78) Dubouchaud H, Butterfield GE, Wolfel EE, Bergman BC, Brooks GA. 2000. Endurance training, expression and physiology of LDH, MCT1, and MCT4 in human skeletal muscle. Am J Physiol Endocrinol Metab 278: E571E579.

79) Armstrong RB, Phelps RO. 1984. Muscle fiber type composition of the rat hindlimb. Am J Anat 171: 259-272.

80) Megeney LA, Neufer PD, Dohm GL, Tan MH, Blewett CA, Elder GCB, Bonen A. 1993. Effects of muscle activity and fiber composition on glucose transports and GLUT4. Am J Physiol Endocrinol Metab 264: E583E593.

81) Dubouchaud H, Eydoux N, Granier P, Prefaut C, Mercier J. 1999. Lactate transport activity in rat skeletal muscle sarcolemmal vesicles after acute exhaustive exercise. $J$ Appl Physiol 87: 955-961.

82) Eydoux N, Py G, Lambert K, Dubouchaud H, Prefaut C, Mercier J. 2000. Training does not protect against exhaustive exercise-induced lactate transport capacity alterations. Am J Physiol Endocrinol Metab 278: E1045E1052.

83) McCullagh KL, Poole RC, Halestrap AP, Tipton KF, O’Brien M, Bonen A. 1997. Chronic electrical stimulation increases MCT1 and lactate uptake in red and white muscle. Am J Physiol Endocrinol Metab 273: E239-E246.

84) Bonen A, McCullagh KJ, Putman CT, Hultman E, Jones NL, Heigenhauser GJF. 1998. Short-term training increases human muscle MCT1 and femoral venous lactate in relation to muscle lactate. Am J Physiol Endocrinol Metab 274: E102-E107. 